\title{
El caso de Mario. De Arquitecto a Artista ${ }^{1}$
}

\author{
María D. Cabrelles² \\ Valencia, España
}

\begin{abstract}
A través de un caso clínico vamos a ir recorriendo un proceso terapéutico basado fundamentalmente en la mentalización sostenida por la importancia de un apego seguro con el terapeuta. El objetivo es entender lo implícito de este procedimiento en relación con las investigaciones en torno al sistema de neuronas espejo y la simulación encarnada. De esta forma se aúnan y explican conceptos puramente psicoterapéuticos junto con consideraciones que provienen de la neurociencia.
\end{abstract}

Palabras clave: alianza terapéutica, apego seguro, mentalización, neuronas espejo.

Through a clinical case, we will describe a therapeutic process consisting mainly on a mentalizationbased treatment on the importance of a secure attachment to the therapist. The aim of this article is to understand the implicit side of this process related to the researches on the mirror neuron system and the embodied simulation. Therefore, we will unite and explain purely psychotherapeutic concepts and other considerations derived from neuroscience.

Key Words: Therapeutic Alliance, Secure Attachment, Mentalization, Mirror Neuron.

English Title: Mario's case: from an Architect to an Artist

\section{Cita bibliográfica / Reference citation:}

Cabrelles, M.D.. (2016). El caso de Mario. De Arquitecto a Artista. Clínica e Investigación Relacional, 10 (2): 465-476. [ISSN 1988-2939] [Recuperado de www.ceir.info ]

DOI: $10.21110 / 19882939.2016 .100208$

${ }^{1}$ Comunicación presentada en la 6a Reunión Anual de IARPP-España, Valencia, Octubre 2015. El texto incluye las ilustraciones de apoyo para la presentación realizadas por Paco Gresa Motilla y María D. Cabrelles.

2 Psicóloga y Psicoterapeuta. Miembro de IARPP-España. Correspondencia: mariadcs@cop.es 


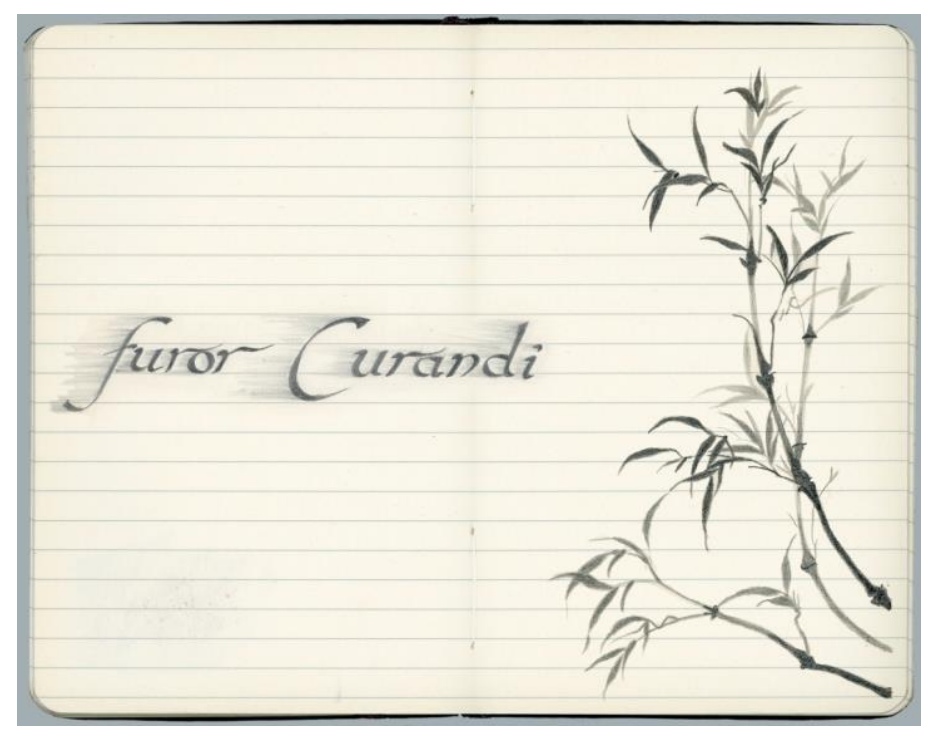

La transición del "furor curandi" a la "lenta germinación de la semilla del bambú", de mi necesidad a la necesidad del otro.

Echando la mirara atrás puedo recordar la urgencia que sentía, como terapeuta novel, por curar el dolor del otro; sin darme cuenta de que en realidad estaba centrada más en mi necesidad de dejar de sufrir por ver y sentir el sufrimiento del otro que en la necesidad del propio paciente. Gracias a la formación, a la práctica clínica y a las experiencias vitales se produjo la transición, natural y necesaria, hasta llegar a centrarme en la necesidad del paciente. De manera que lo que en un primer momento era una sensación de apremio porque el proceso terapéutico fuera rápido pasó a ser un proceso de atención, mirada y escucha, donde lo primordial era que el paciente se sintiera mirado, escuchado, sentido, comprendido, acogido... seguro. Lo importante era convertirme en una base segura para el paciente. Esa base segura es como las raíces del bambú, que crecen despacio pasando inadvertidas bajo tierra. Raíces que tras haberse desarrollado profundamente permiten que el crecimiento de la planta sea asombroso. De la misma manera que esta planta crece, se despliega y se desarrolla así el paciente puede ir creciendo, sustentado por esa base, aprendiendo a relacionarse consigo mismo y con el mundo, desplegándose.

En las sesiones de supervisión de casos ante las preguntas de mi supervisor sobre los pacientes siempre respondía empezando con la frase: "pues fíjate... es como un cachorro herido..., o es como un niño temeroso de mirada huidiza, o como una niña que busca anhelante la mirada de aprobación de un adulto de referencia...". Recuerdo que él me señaló: "¿pero es que tú ves a todos tus pacientes como niños?". Y la verdad es que sí, ¿quién entra por la puerta? De alguna manera el adulto que hay en cada paciente trae de 
la mano a un niño con necesidades, con una fractura narcisista. ¿Qué es lo que no tuviste? ¿Qué te faltó? ¿Qué te sobró? ¿Cuál es tu historia?

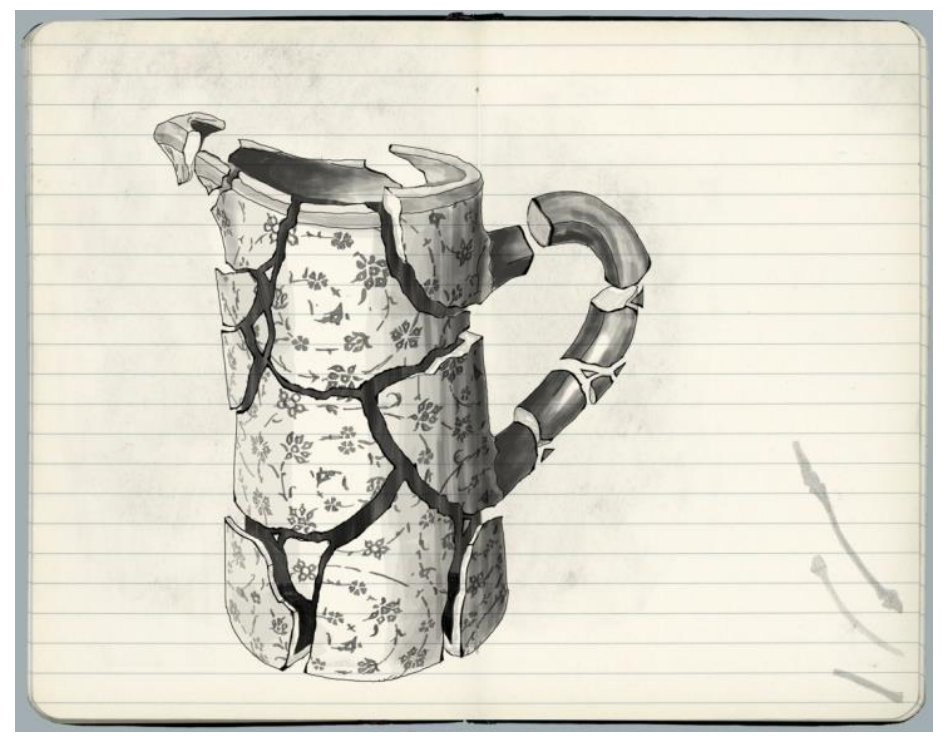

Y con esa mirada y esa actitud mentalizadora recibí a Mario...

Recuerdo la primera vez que le vi entrar por la puerta de mi consulta. Sus movimientos eran pequeños, cortos, rígidos y tensos. Todo en él transmitía miedo, inseguridad y mucha timidez. Podía sentir lo encogido que se sentía.

Nació en un pueblo pequeño de la España profunda. Es el segundo de dos hermanos, de los cuales su hermana es 4 años mayor que él. En el momento de comenzar la psicoterapia tiene 29 años y sigue viviendo con sus padres.

Consciente de la importancia esencial del vínculo en la psicoterapia le miro y le escucho. Desde el principio puedo sentir su fragilidad y su necesidad de una base segura, de un apego seguro, así que me centro en ir estableciendo una sólida confianza básica y una buena alianza terapéutica... Sin prisa... Con tranquilidad... Atendiendo a su fractura.

Su línea de vida está tachonada de hitos vitales potencialmente traumáticos además de que sus principales figuras de referencia, sus padres, no fueron unos padres suficientemente responsivos, ni afectivamente disponibles y no constituyeron para él una base segura; no fueron unas figuras de apego seguro (Main, 2011).

El accidente de un primo de 18 años, teniendo él 7 años, con el consiguiente terremoto emocional familiar. Los insultos y la mirada de reprobación por parte de sus iguales en el Instituto haciendo referencia a su homosexualidad. La mirada de decepción, de desaprobación y de exigencia de su padre. El suicidio de un primo suyo y el intento de suicidio de su hermana mayor, un año después de declarar su orientación lésbica ante la 
familia. Padecer un cáncer de testículo y superarlo. Y finalmente, ya en la edad adulta, la crisis económica y social de los últimos años, que también se lo llevó por delante y de arquitecto trabajando en un estudio se quedó sin trabajo y tuvo que reinventarse.

Y así, con esta historia vital, Mario llega a consulta diciendo: "No puedo disfrutar de ser quien soy, ni de lo que soy". "Me siento pequeño". "Cuando entro en mi casa (residencia familiar de origen en la que vivía con sus padres) me vuelvo más y más pequeño. Siento que me encojo".

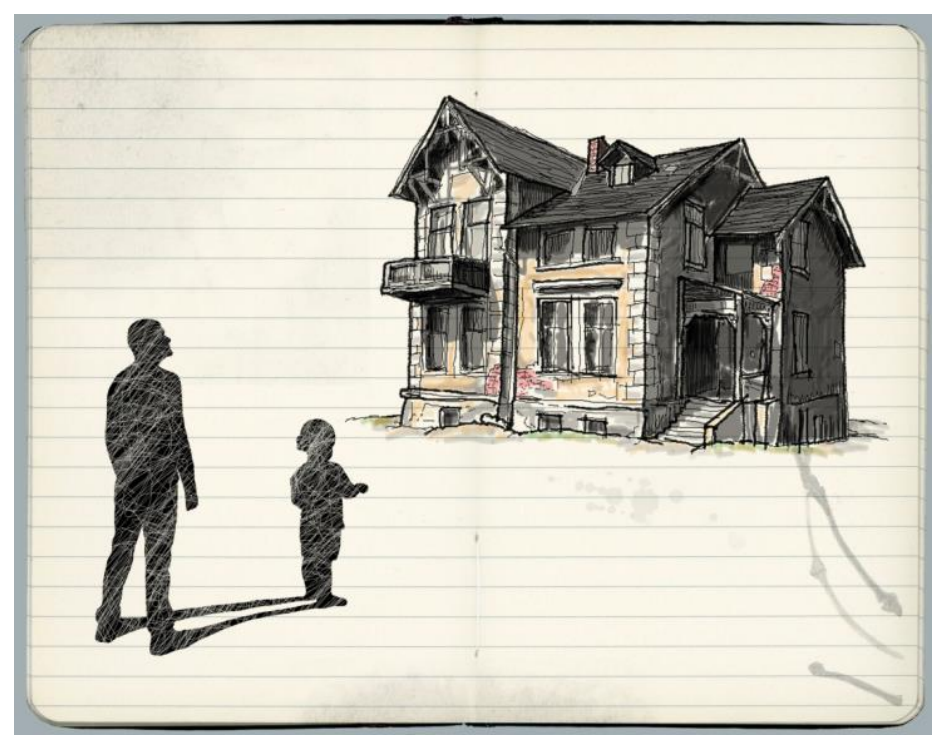

Al llegar la crisis profesional decide dedicarse a algo que siempre le había interesado: el arte, la cerámica. Pero se siente un intruso en el mundo del arte, se siente inadecuado. "Soy un caracol que me escondo". Teme no estar a la altura de sus propias expectativas. Es autocrítico en exceso. Declara tener miedo al éxito, tiene vértigo ante el éxito y al reconocimiento público, se hace pequeño ante la mirada de los otros, aunque sea una mirada de admiración. La crítica insana, y con esto se refiere a las exigencias del padre de que se dedique a un trabajo de provecho y remunerado, desencadenan lo que él denomina el "modo caracol". Dice Mario: "Me siento herido y me retraigo". Con la mirada siente que su padre le dice: "No eres el hijo que yo querría tener".

Sufre de ansiedad anticipatoria ante los encuentros sociales, aunque "una vez hago click me lanzo y todo sale bien". En su nueva vertiente profesional está teniendo un reconocimiento que le sobrecoge. "Todo va demasiado deprisa". "Ante una oferta importante de trabajo la respuesta es ino!". Y "si me fuerzan me resisto". "Cuando siento que me exigen me encojo". 


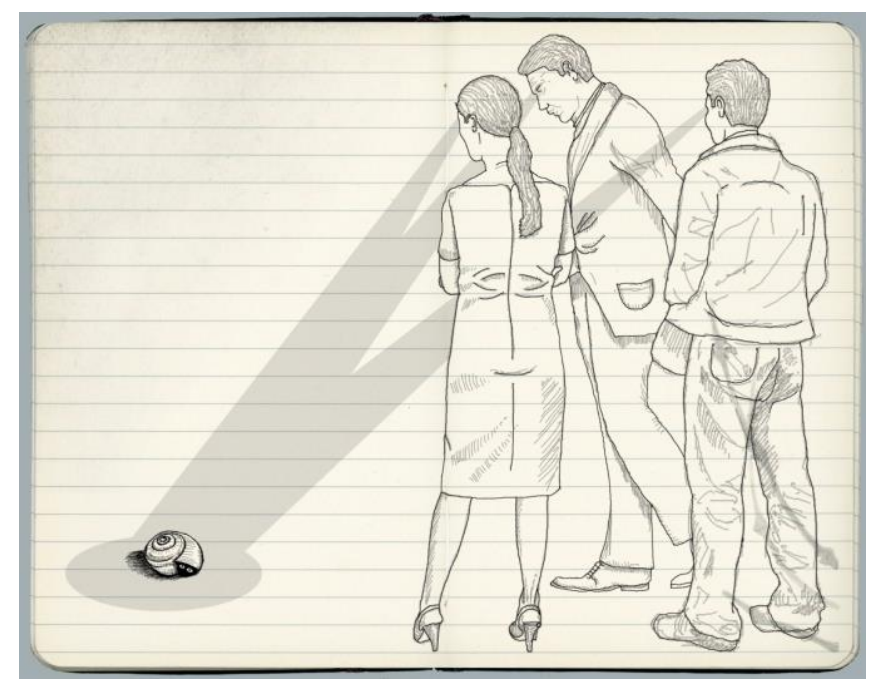

Toda esa primera etapa exploratoria de proceso terapéutico consistió en mantenerme disponible de manera elástica y atenta, que se sintiera escuchado, visto y sentido. Que sintiera mi presencia incondicional dispuesta "a escucharle y a compartir, sin censuras y sin rechazos, sus contenidos inconscientes, inconfesables o simplemente existenciales" (Cencillo, 1988, p.180). O como dirían actuales estudiosos del psicoanálisis relacional, como Coderch (2012) y Fonagy (1999), mentalizando con él, intentando sentir lo que él sentía y que me sintiera ahí, disponible.

Una vez que contra-transferencialmente empecé a sentir por dónde enfocar el caso avanzamos en la psicoterapia. Mi actitud especularizante (Fonagy, 1999) a través de la comunicación verbal y no verbal, fue haciendo que Mario se viera, se sintiera y se explicara a sí mismo de una manera diferente.

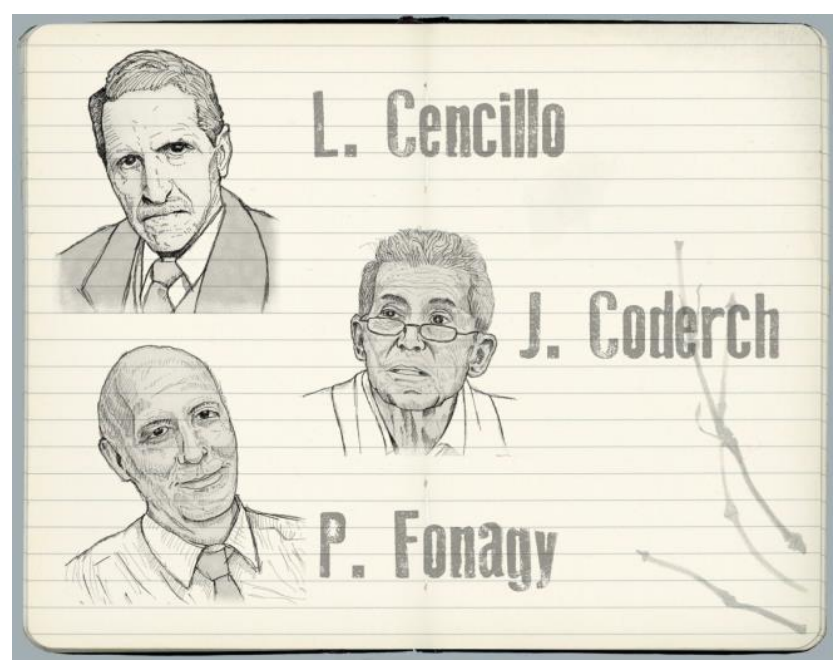


Gallese, Eagle y Migone (2006) lo explican muy bien a través del sistema de neuronas espejo y la simulación encarnada. Según estos autores el sistema de neuronas espejo sería el que se activa siempre que estamos en relación con otro, permitiendo que las mismas áreas neuronales que se activan en el paciente cuando está en consulta se activen a su vez en el terapeuta. De esta forma, y de una manera prerreflexiva e implícita, a través de la simulación encarnada automática se produce una suerte de bucle de simulaciones encarnadas en las que se ven envueltos paciente y terapeuta. Ambos, influyendo uno en el otro... Pero con una salvedad, sugiero que, aunque se activen las mismas áreas neuronales cada uno de los implicados tiene unas conexiones neuronales diferentes. De forma que el paciente puede "verse" representado en la mente del terapeuta y puede llegar a sentir lo vivido de una manera más regulada, más contenida.

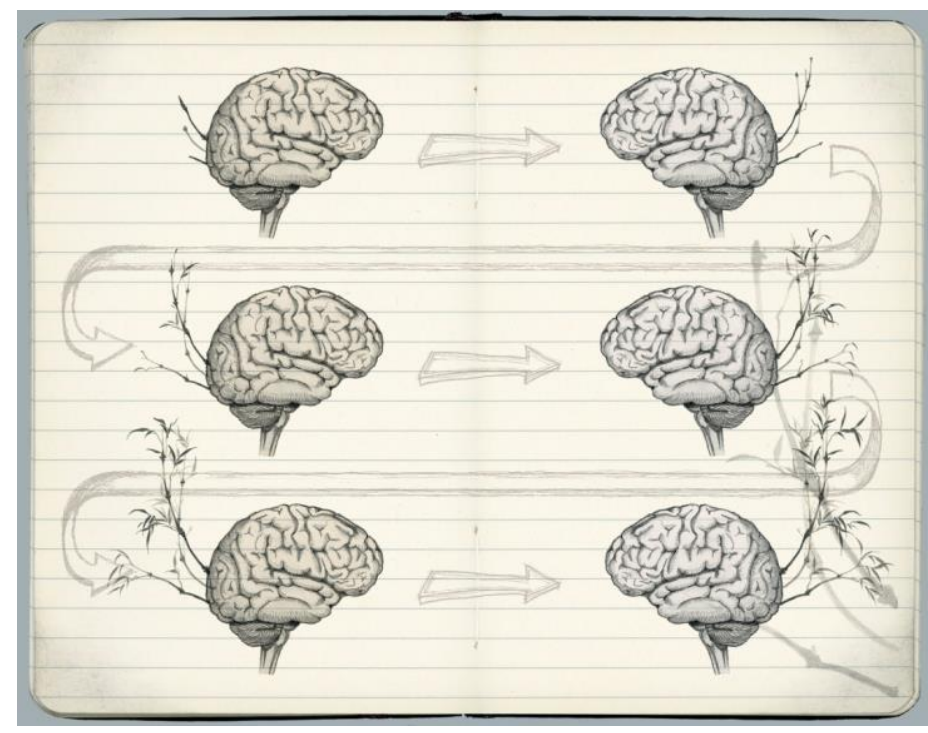

En este punto señalar la vigencia de la Psicoterapia Dialytica de Luis Cencillo que ya en 1988 hablaba sobre la actitud adecuada del terapeuta en consulta: "(...) basta con estar el terapeuta entonado durante las sesiones", "sólo se requiere que el terapeuta se entregue a su obra y ponga en ella lo mejor de sí mismo (... y) que eso "mejor" no quede en la racionalidad"(p.130). Además la dialysis de la que hablaba el profesor Cencillo (1988) la definía como: 


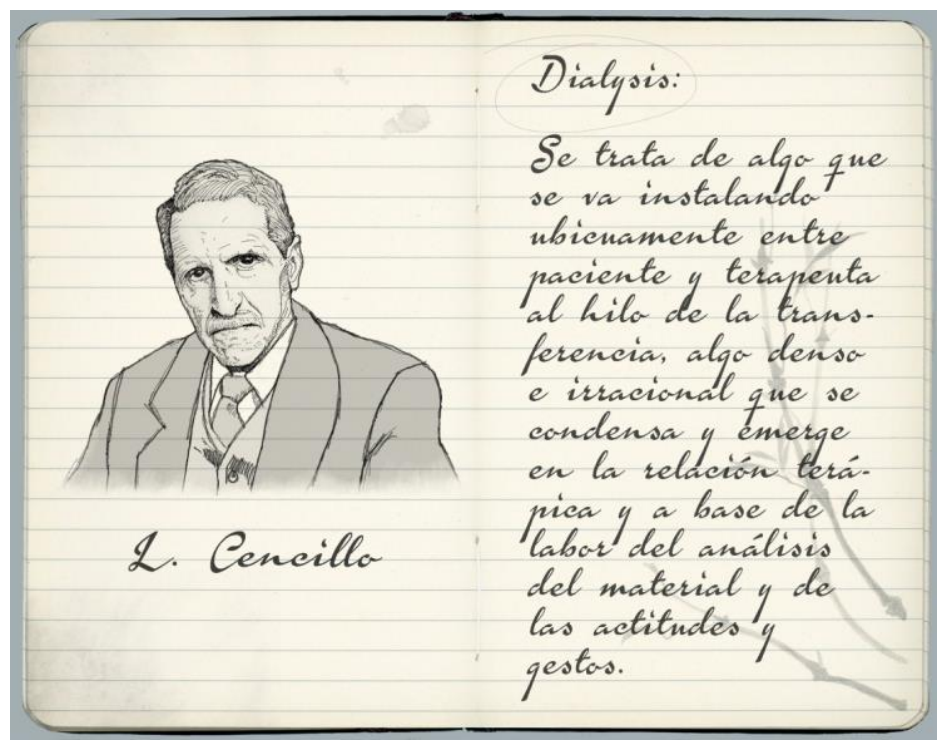

Se trata de algo que se va instalando ubicuamente entre paciente y terapeuta al hilo de la transferencia, algo denso e irracional que se condensa y emerge en la relación terápica y a base de la labor del análisis del material y de las actitudes y gestos. (p.194)

Esta relación es la que permitiría de manera prerreflexiva, a través de la simulación encarnada, elaborar y regular en y con el otro la vivencia de la propia experiencia vital, además de elaborarlo de manera explícita analizando el material aportado por el paciente, explicitando lo implícito.

Esa fue la forma en la que Mario empezó a establecer una nueva manera de vincularse, de relacionarse con el mundo, a través del establecimiento de una base segura con una nueva figura de referencia, aquella en la que me había convertido como su psicoterapeuta, una figura de apego seguro. Y así, sesión a sesión, mirada a mirada, fue practicando una nueva manera de relacionarse, su cerebro fue creando nuevas conexiones neuronales que fueron ampliando sus capacidades relacionales de una forma implícita (Riera, 2011). 


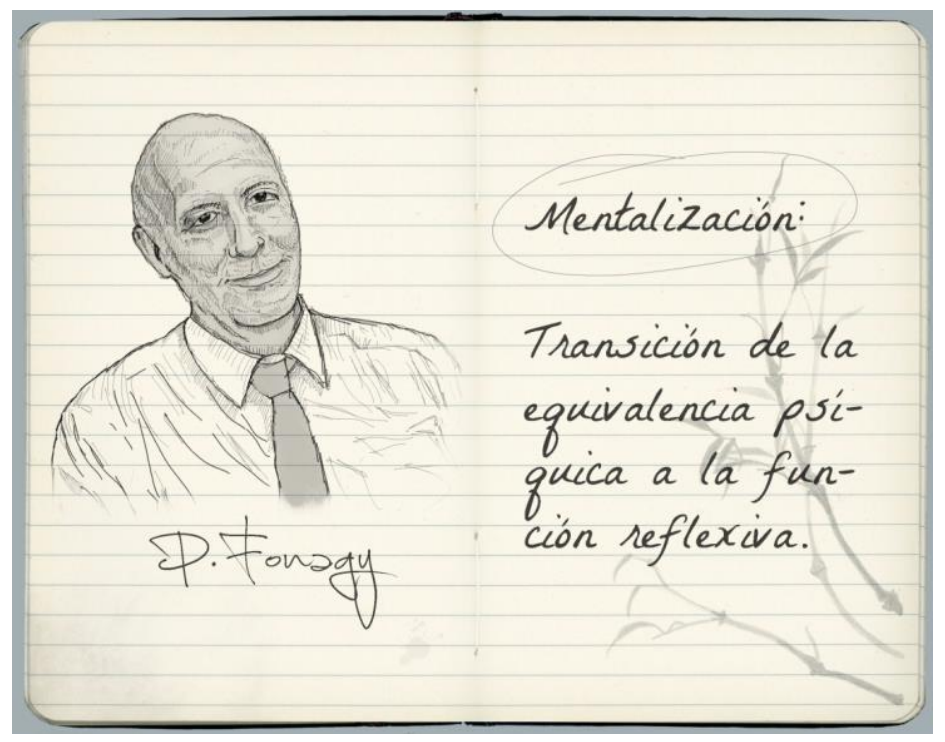

Sin lugar a dudas lo fundamental en todo el proceso psicoterapéutico ha sido la mentalización. P. Fonagy lo explicaría como una transición de la equivalencia psíquica a la función reflexiva (1999). Cuando Mario empezó la psicoterapia se vivía a sí mismo como insignificante, las conexiones neuronales que se activaban ante la mirada del otro le recordaban una y otra vez su pequeñez. No importaba que las nuevas miradas fueran diferentes: de amabilidad, de reconocimiento y de admiración, porque en él ya se había activado su sensación de pequeñez. Mario permanecía en esa fase de equivalencia psíquica, en la que aquello que sentía se correspondía con la realidad. Y no sólo eso, sino que cuando un destello de la mirada de admiración por su obra, conseguía conectar con él, la disonancia entre el sentimiento de base y la nueva sensación le provocaban una inestabilidad y una sensación de irrealidad que le resultaban inquietantes y difíciles de integrar.

A través de una nueva mirada comprensiva y compasiva, en un primer momento de los "nuevos" otros, luego de su psicoterapeuta y finalmente la suya propia, fue desarrollando ese yo reflexivo y la capacidad de mentalizar. Entendió por qué sus figuras de referencia son como son, que sus padres dieron la mejor versión de sí mismos como figuras de apego, que hicieron lo que pudieron dada su propia historia vital, las propias figuras de referencia que tuvieron y el tipo de apego que sus referentes fueron capaces de darle. Algo que explicó muy bien M. Main con el desarrollo de la EAA, Entrevista de Apego Adulto (2011). Esto le ayudó a entender a sus padres, a dejar de esperar, a dejar de reivindicar, a hacer el duelo por los padres ideales que nunca tuvo y nunca tendrá. 


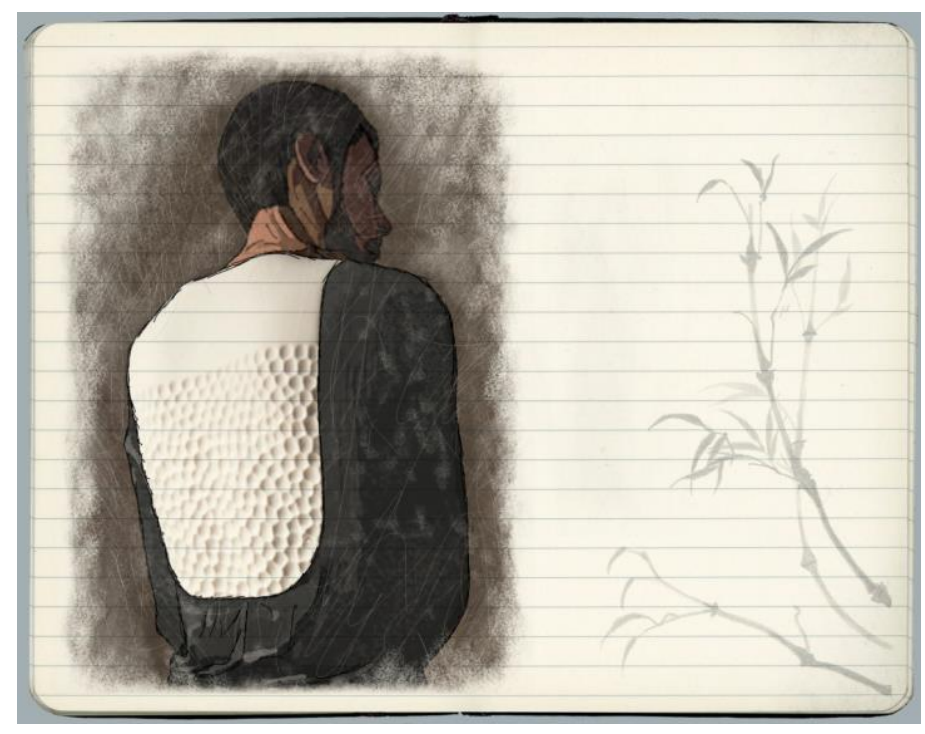

En la transición, para aguantar las miradas de los otros tuvo que hacerse literalmente una armadura de cerámica, con la que acudía a las exposiciones de sus obras durante los dos primeros años. ¡Qué simbólico! Gran parte de su producción artística gira en torno a toda una colección de exoesqueletos. Desde luego su obra es él.

Con esta nueva mirada mentalizadora y después de haberse dolido por la pérdida de lo que nunca tuvo, Mario empieza a permitirse mirarse y conectar con el reconocimiento público y profesional que ya estaba teniendo y del que no podía disfrutar al prevalecer el apego original.

De arquitecto a artista. Pasó de ser un niño sensible y marginado a tener al mundo del arte a sus pies.

Ahora es un auténtico placer escuchar, sentir y ver la expansión de Mario, cómo ocupa el espacio por el que se desplaza, cómo por fin respira el aire que le rodea a pleno pulmón, cómo se ríe a carcajadas cuando antes sólo se sentía invadido y atenazado por la congoja y no podía ni reír ni llorar.

Donde antes escuchaba:

"No puedo disfrutar de ser quien soy ni de lo que soy", "Me siento pequeño". "Quiero llorar y no puedo". "Me encojo". 


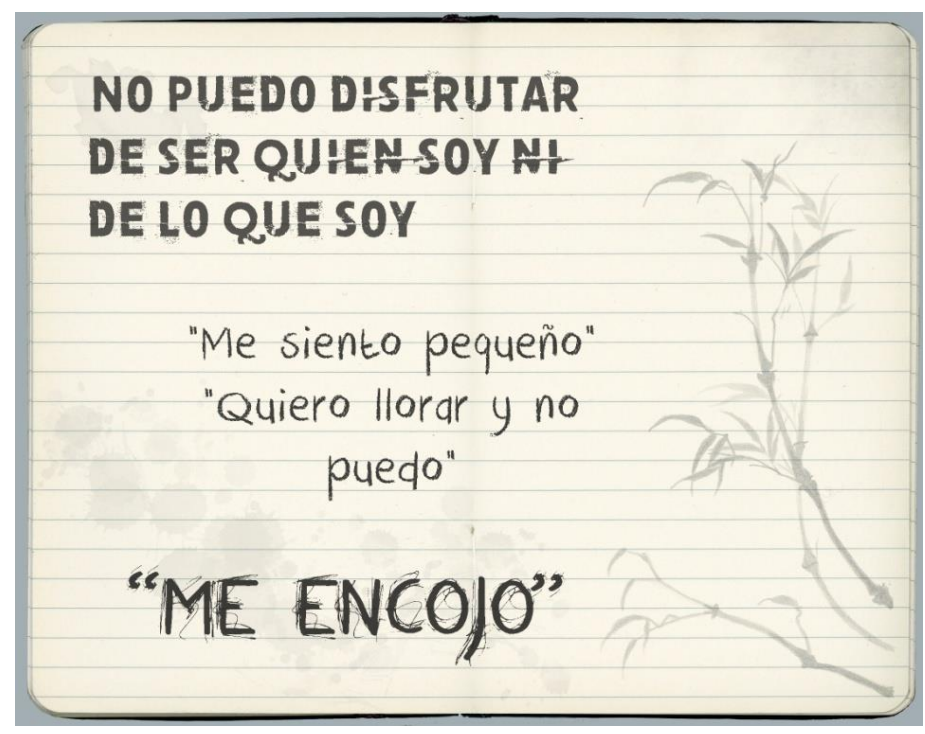

Ahora escucho:

"Tengo ganas de ir a consulta y reírme contigo", "Ya no me pasa lo de antes... Ahora disfruto de todo lo que me está pasando". "Ahora sí que creo que lo que está pasando me está pasando a mí". "¡Ahora ya soy artista María!" "joder!, iya me lo voy a creer!"

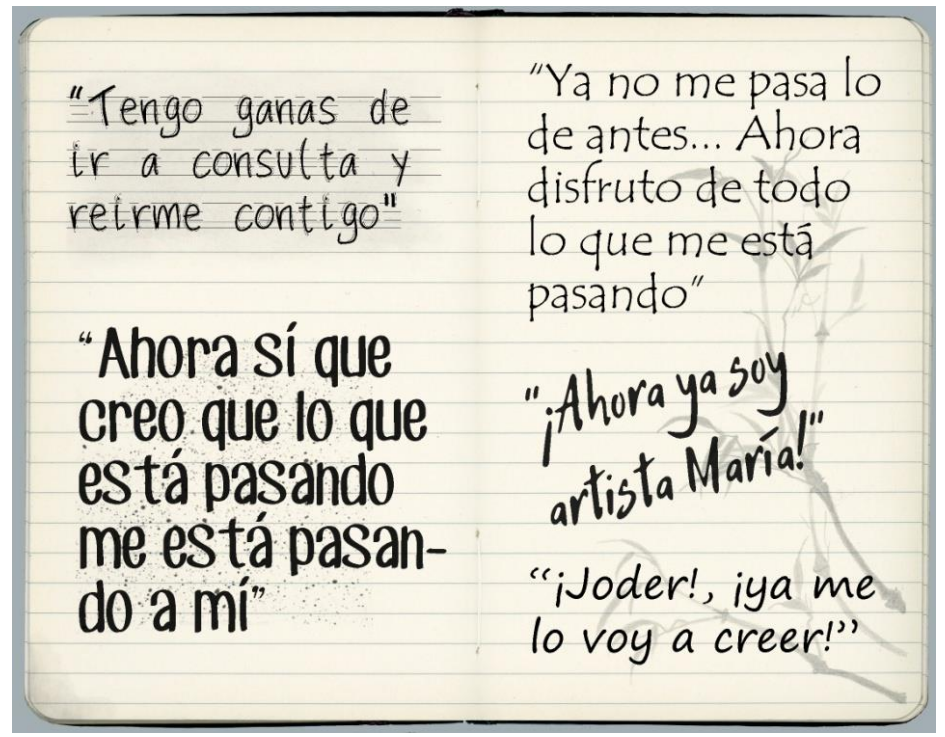

Y él escucha:

"¡Mario, has crecido! ¡Estás más alto!" "¡Te ha cambiado el tono de voz!". 


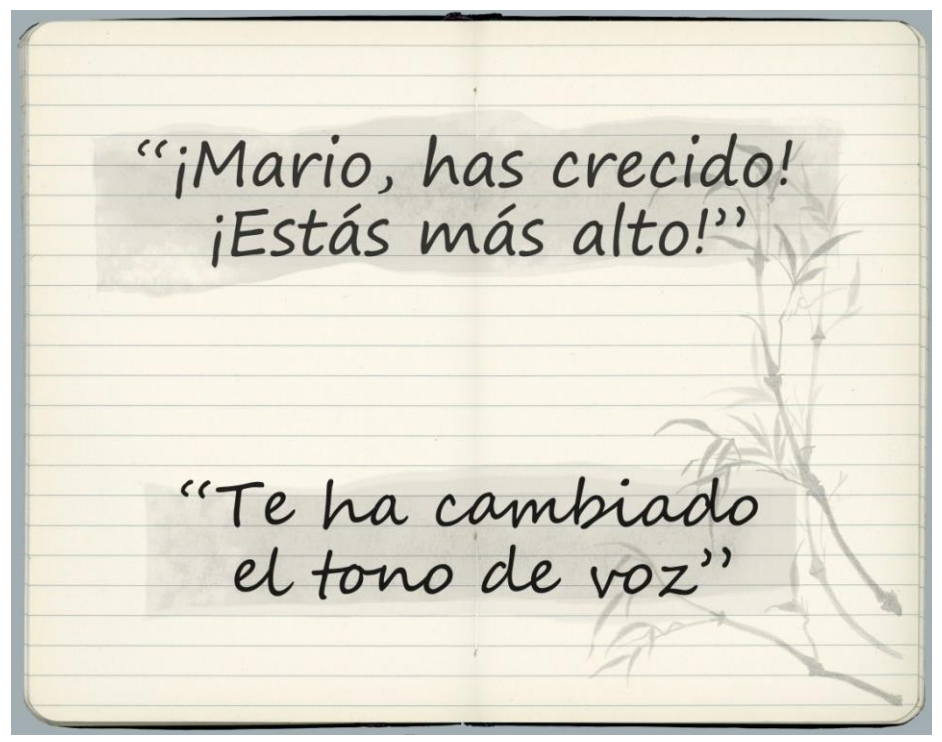

Del "trabajo de restauración del self" (Guerra, 2014, p.9) del paciente que se produce durante el proceso psicoterapéutico surge "alguien con un mayor conocimiento de sí mismo, de los diferentes estados de su self y la vivencia de estos como congruentes aunque distintos" (Guerra, 2014, p13).

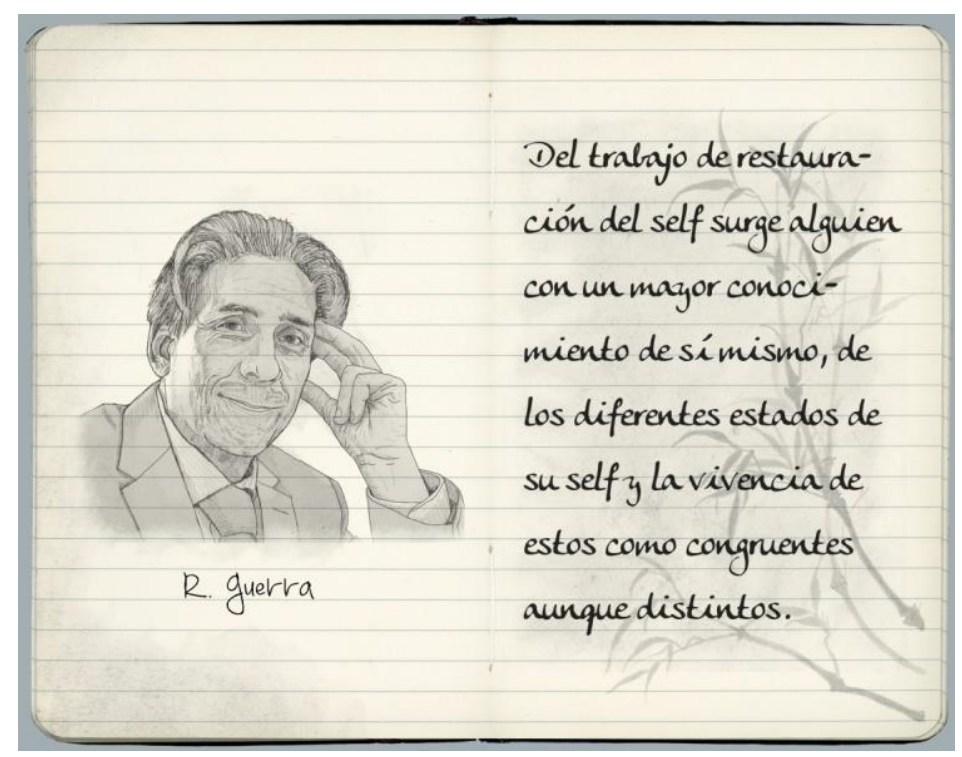

El mismo Mario declara lo que siente que le está pasando durante la psicoterapia haciendo referencia al Kintsugi, técnica artística de la cultura japonesa mediante la cual, al romperse una pieza de cerámica, es reparada uniendo sus piezas con oro; proceso que revaloriza la obra. 


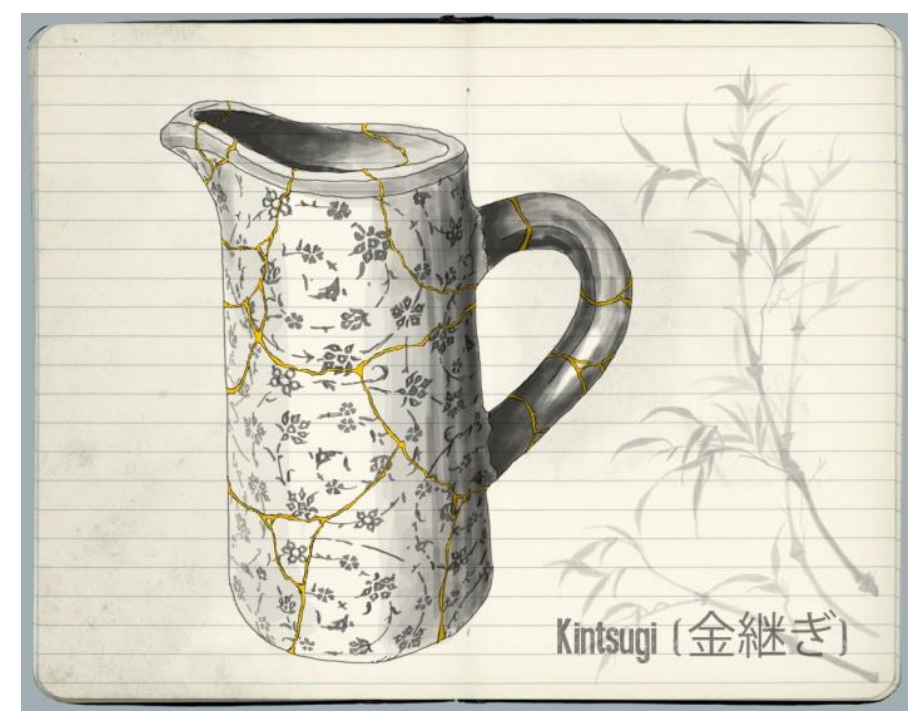

Así es como él se siente, re-construyéndose, re-valorándose, con una fortaleza mayor.

\section{REFERENCIAS}

Cencillo, L. (1988). La práctica de la psicoterapia. Madrid, España: Ed. Marova.

Coderch de Sans, J. (2012). Realidad, Interacción y Cambio psíquico. Madrid, España: Ágora Relacional S.L.

Fonagy, P. (1999). Persistencias transgeneracionales del apego: Una nueva teoría. Aperturas psicoanalíticas. Recuperado de: http://www.aperturas.org

Gallese, V.; Eagle, M.; Migone, P. (2007). Entonamiento emocional: neuronas espejo y los apuntalamientos neuronales de las relaciones interpersonales. Aperturas psicoanalíticas, 026. Recuperado de: http://www.aperturas.org

Gresa, P.; Cabrelles, M.D. (2015). Idea y realización de imágenes para el presente artículo.

Guerra, L.R. (2014). La insoportable levedad del self. Revista digital de Medicina Psicosomática y Psicoterapia, 4 (1). Recuperado de: http://www.psicociencias.com

Main, M. (2000). Las categorías organizadas del apego en el infante, en el niño, y en el adulto; atención flexible versus inflexible bajo estrés relacionado con el apego. Aperturas psicoanalíticas, 008. Recuperado de: http://www.aperturas.org

Riera, R. (2011). La conexión emocional. Barcelona, España: Ed. Octaedro.

Original recibido con fecha: 13/5/2016 Revisado: 17/5/2016 Aceptado: 30/6/2016 